\title{
REAVI
}

\section{MÉTODOS DE PESQUISA: UMA AVALIAÇÃO EM ARTIGOS DE MARKETING SOBRE MARCA}

\author{
Ericsson Oliveira ${ }^{1}$, Ricardo Gomes da Silva ${ }^{2}$, Rita Mateus ${ }^{3}$, Rodrigo da Silva Monteiro ${ }^{4}$, Irene Raguenet Troccoli $^{5}$ \\ Universidade Estácio de Sá $1,2,3,4,5$ \\ ericssonssdig.com.br ${ }^{1}$, ricardo.atica@uol.com.br ${ }^{2}$, ritamateus.rjegmail.com ${ }^{3}$ \\ monteiroadm83egmail.com ${ }^{4}$, irene.troccolidestacio.br ${ }^{5}$
}

\begin{abstract}
Resumo
Objeto de inúmeras pesquisas na área de Marketing, o construto marca, enquanto símbolo, tornase capaz de se impregnar de significados para serem veiculados ao consumidor e de expressar a visibilidade de um discurso interno. Esta popularidade levanta a curiosidade em relação aos métodos utilizados nas pesquisas a respeito: conhecê-los auxilia no seu aprofundamento futuro ou na sua complementação por meio de caminhos que tenham sido pouco explorados ou permanecido inexplorados. O presente artigo descritivo-quantitativo identifica as principais características metodológicas dos estudos científicos brasileiros de Marketing disponíveis na base SPELL publicados sobre o tema "marca" durante 11 anos. Conclui-se que houve descaso na apresentação de várias destas informações. Isto sugere a necessidade de reforço no ensino de métodos de pesquisa nos ambientes acadêmicos, de forma a conscientizar, tanto autores quanto avaliadores, quanto à importância da credibilidade, da transferibilidade, da confiança e da confirmabilidade de qualquer pesquisa científica.
\end{abstract}

Palavras-chave: Marca. Valor da Marca. Metodologia da Pesquisa.

\section{SEARCH METHODS: AN EVALUATION IN BRAND MARKETING ARTICLES}

\begin{abstract}
As a symbol, the brand becomes capable of impregnating itself with meanings to be conveyed to the consumer and of expressing the visibility of an internal discourse. The objective of this research is to identify the main methodological characteristics of Brazilian scientific studies of Marketing published on the "brand" theme for 11 years. We conclude that there was a lack of presentation of several of this information. This suggests the need to reinforce the teaching of research methods in academic environments, in order to make both authors and evaluators aware of the importance of credibility, transferability, trustworthiness, and confirmation of any scientific research.
\end{abstract}

Keywords: Brand. Brand Equity. Research Methodology.

\section{Introdução}

Uma das formas de as organizações obterem vantagem competitiva e se diferenciarem da concorrência se dá por meio das marcas, que se apresentam imbuídas de uma série de valores, de associações e de significações. Por isso mesmo, os profissionais de Marketing referenciam a

Revista Eletrônica do Alto Vale do Itajaí - REAVI, v.08, n 13, p. 030-047, dez 2019 ISSN: 23164190, DOI 10.5965/2316419008112019030 


\section{REAVI}

importância deste construto, principalmente pela necessidade de agregar valor aos produtos e aos serviços (CHEKALINA; FUCHS; LEXHAGEN, 2018).

Assim, nesta gestão estratégica de marcas, o que se busca é estabelecer o elo entre elas e o consumidor, direcionando a maneira pela qual este vai percebê-la e como a marca pode envolvêlo por meio de seus atributos. Desta forma, a marca extrapola a sua simples representação gráfica, na medida em que estabelece um padrão de associação mental de valores com o consumidor. Enquanto símbolo, torna-se capaz de se impregnar de significados para serem veiculados ao consumidor e de expressar a visibilidade de um discurso interno, que envolve atitudes, posturas e valores organizacionais, extrapolados para serviços, produtos e processos na linha de produção, afirmam (RAITHEL; TAYLOR; HOCK, 2016).

Os consumidores aprendem sobre marcas por meio de experiências anteriores e descobrem quais delas satisfazem suas necessidades e quais deixam a desejar. $O$ resultado é que as marcas se tornam um meio rápido para simplificar as decisões dos consumidores, reduzindo custos de busca, tanto internamente (em termos de quanto têm de pensar) quanto externamente (em termos de quanto tem de procurar) (YANG; LIU; LI, 2015).

Este poder das marcas é tão forte que elas podem chegar a se tornar dispositivos simbólicos que permitem aos consumidores projetar sua autoimagem. Usar uma marca passa a representar uma associação a determinados tipos de pessoa, refletindo diferentes valores ou ideias. Ou seja, o consumo de uma marca torna-se um meio pelo qual os consumidores podem comunicar a outros — ou até a si próprios — o tipo de pessoa que são ou que gostariam de ser (NYADZAYO; KHAJEHZADEH, 2016).

Muitas decisões do consumidor não se concentram apenas nos atributos da marca, mas também nos sentimentos e nas emoções associadas à aquisição ou à utilização da marca, e até mesmo na situação em que o produto é comprado ou utilizado. Desta forma, uma marca pode ser escolhida não apenas por um atributo (preço, estilo, características funcionais), mas porque faz com que o consumidor se sinta bem ou com que seus amigos gostem (DANAEI; SOURANI, 2016).

À luz destes elementos, o presente estudo busca responder à seguinte questão-problema: quais são as principais características metodológicas dos estudos científicos brasileiros publicados de Marketing sobre o tema marca, nos últimos 11 anos?

Ao levantar informações sobre as características dos métodos adotados por autores brasileiros que se dedicaram ao tema, escrevendo artigos científicos a respeito, objetiva-se obter retrato que deverá ser profícuo àqueles que se interessarem em continuar a pesquisar nesta área. Isso porque, sabendo a priori quais as formas já priorizadas, eles poderão aprofundá-las ou complementá-las, optando por caminhos que tenham permanecido inexplorados ou que tenham sido pouco explorados. Em outras palavras, o presente artigo se propõe a auxiliar no avanço científico dos pesquisadores dedicados ao construto marca sob a ótica de Marketing.

Este breve relato a respeito de marcas sugere que se trata de assunto interessante à pesquisa em Marketing, o que se tem observado na prática. Por exemplo, uma busca realizada na base Scopus em setembro de 2019 com o termo brand no título de artigos publicados entre 2015 e 2019 retornou 5.760 resultados, dos quais 3.719 enquadrados na área de negócios, administração e contabilidade. Uma pesquisa para artigos de administração com a palavra "marca" também no título, para o mesmo período, na base Spell retornou 125 resultados.

Assim, se o assunto é de tamanho interesse científico, é lícito haver curiosidade sobre as formas como os autores realizam estas pesquisas. Mapear as formas de pesquisa contribui ao conhecimento do estado da arte de determinado assunto, o qual pode ser usado como um Revista Eletrônica do Alto Vale do Itajaí - REAVI, v.08, n 13, p. 030-047, dez 2019 ISSN: 23164190, DOI 10.5965/2316419008112019030 


\section{REAVI}

instrumento de reconhecimento e interpretação da realidade, como uma proposta metodológica documental e como base para a tomada de decisão no campo da investigação. E, dentre os passos necessários à realização de um estado da arte, encontra-se o mapeamento das linhas de investigação, cujo conhecimento pode ajudar futuros pesquisadores que se interessem pelo assunto a buscarem caminhos eventualmente alternativos, como forma de contribuírem à ciência ao alcançarem resultados inéditos (MONTOYA, 2005).

Para tanto, ele se encontra estruturado da seguinte forma: introdução, referencial teórico referente ao construto marca, método, resultados e discussão dos resultados.

\section{Referencial teórico}

Embora as marcas traduzam uma realidade histórica com alguma expressividade e extensão espaço-temporal, a teorização do conceito constitui-se como fenômeno relativamente recente. Prova disto é que sua primeira articulação aprofundada fortemente, associada à noção de imagem de marca, foi desenvolvida há cerca de apenas seis décadas, por Gardner e Levy (1955). Pouco depois, marca foi definida pela American Marketing Association (AMA) como nome, termo, sinal ou símbolo, ou como a combinação desses, que objetivava identificar mercadorias e serviços de um vendedor ou grupo de vendedores e diferenciá-los dos competidores (AMA, 1960).

Criticada por ser muito voltada àquilo que estava sendo transacionado entre as partes, esta definição viria ser revista, até porque, tratava-se de forma de raciocinar considerada periférica em relação ao Marketing, insuficientemente desenvolvido para ser incorporado na linguagem e nas práticas profissionais (BERTILSSON; RENNSTAM, 2018).

Com isto, marca passou a ser entendida como um nome, termo, design, símbolo ou qualquer outra característica que identifique o bem ou serviço de determinado vendedor como distinto daquele de outro vendedor (AMA, 2014). Mais modernamente, Conejo e Wooliscroft (2015) reconceitualizaram marcas como sistemas semióticos de Marketing que geram valor: seriam construções multidimensionais complexas com diferentes graus de significação, de independência, de cocriação e de escopo, que geram valor para os participantes diretos e indiretos, para a sociedade e para o ambiente em geral, por meio do intercâmbio de significados cocriados.

No caso da definição da AMA, por meio da adição das palavras "ou qualquer outra característica", que permitem a inclusão dos intangíveis — por exemplo, a imagem — o foco fundamental passou a dirigir-se ao propósito da marca, que é a diferenciação (WOOD, 2000; THEURER et al., 2018). Assim, passou-se a entender que a diferenciação da oferta da empresa deixou de ser o caráter distintivo da marca, passando a ser a essência do produto, cujo significado e direção definem a identidade, no tempo e no espaço, daquilo que está sendo ofertado (BLACK; VELOUTSOUB, 2017).

A consciência da marca — ou seja, a habilidade de identificá-la (KELLER; MACHADO, 2006) - envolve distingui-la e mantê-la na memória, com sua imagem definindo-se como "um conjunto de associações relacionadas à marca que consumidores retêm na memória" (KELLER, 1993, p. 2). Isto pode gerar o envolvimento do cliente, o que é relevante, tendo-se em conta que este comprometimento é um dos fatores que influencia a resposta em relação a uma marca (BOWDEN; DAGGER; ELLIOTT, 2009; PALMER, 2010). No caso, o envolvimento pode ser relacionado ao produto, à mensagem ou ao indivíduo que os percebe; por exemplo, um produto de baixo envolvimento é aquele adquirido sem grande reflexão por parte do cliente, não lhe envolvendo o ego nem muito dinheiro - por consequência, uma eventual má decisão de compra neste caso não implicaria maiores arrependimentos.

Revista Eletrônica do Alto Vale do Itajaí - REAVI, v.08, nº 13, p. 030-047, dez 2019 ISSN: 23164190, DOI 10.5965/2316419008112019030 


\section{REAVI}

Um dos aspectos mais pesquisados no que tange ao construto marca, pelos ângulos tanto acadêmico quanto da prática administrativa, é o de valor da marca — em inglês, brand equity (RAGGIO; LEONE, 2007; SHANKAR; AZAR; FULLER, 2007). Este construto já aparecia em alguns trabalhos de Marketing na primeira metade da década de 1980, ganhando notoriedade a partir de 1988, quando o Marketing Science Institute (MSI) realizou congresso específico sobre o assunto.

Definido como o valor total de uma marca como um ativo quando é vendido ou incluído em um balanço, remetendo, portanto, à avaliação de marca (FELDWICK, 1996), brand equity é a preferência diferencial e a resposta ao esforço de Marketing que um produto obtém devido à sua identificação de marca em comparação com a preferência e a resposta que esse mesmo produto obteria se não tivesse a identificação de marca (DATTA; AILAWADI; HEERDE, 2017). Sua importância advém de o branding usualmente ser considerado atividade gerencial prioritária, com base na premissa de que as marcas são um dos ativos intangíveis mais valiosos que as empresas possuem (KELLER; LEHMANN, 2006; KELLER, 2016).

As diferentes abordagens definidoras do brand equity podem se originar de duas percepções diferentes (CHRISTODOULIDES; DE CHERNATONY, 2010): a do consumidor e a da empresa, essa última sempre com foco financeiro. Pela percepção do consumidor, trata-se de algo multidimensional, remetendo à força da marca ou ao seu tamanho (FELDWICK, 1996), ou a benefícios simbólicos da marca para o consumidor (OLIVEIRA-CASTRO et al., 2008). Representa reações atitudinais dos consumidores sobre seu valor (KELLER, 2016), e sinaliza os benefícios econômicos e ou sociais àquele que obtenha ou use a marca (PORTO, 2018). Por isso mesmo, uma marca com brand equity positivo obtém mais respostas favoráveis dos clientes do que uma versão do mesmo produto ou serviço que não conte com este predicado (KELLER; MACHADO, 2006).

A lealdade à marca, a qualidade percebida, o conhecimento da marca e as associações positivas à marca são as dimensões mais comuns do brand equity, mas a literatura aponta que existem outras complementares - por exemplo: a exclusividade e a disposição a pagar preço premium (PORTO, 2018). Por seu turno, uma das maiores discussões sobre brand equity em Marketing tem a ver com sua mensuração. Trinta (2006) ressalta que, embora existam várias formas de mensuração, nenhuma forma de cálculo possui plena aceitação. Até os modelos exclusivamente financeiros não apresentam unanimidade, uma vez que os padrões de avaliação do intangível variam segundo países, empresas, setores, ambiente competitivo e conjuntura. Além disso, a existência de diversas abordagens também se deve à existência de distintos objetivos relacionados à utilização do valor da marca.

Uma das sugestões para se executar esta avaliação afirma que isto pode ser feito de duas formas: 1) usando percepções do consumidor, quando se mede o que os consumidores pensam e sentem sobre a marca; ou 2) usando informações sobre os níveis de vendas, com a marca sendo estudada com base em modelo de participação de mercado. No primeiro caso, a avaliação pode ser executada por meio da abordagem direta, quando se tenta medir o brand equity pelo acesso mais direto do impacto do conhecimento da marca na resposta do consumidor para diferentes elementos do programa de Marketing da firma (DATTA; AILAWADI; HEERDE, 2017).

Outro aspecto relevante diz respeito à valorização das marcas enquanto fator determinante na estratégia para atração e retenção de clientes (LEÃO; CAMARGO; CAVALCANTI, 2014), conforme elas possam adquirir personalidade, passando a deter características humanas (AAKER, 1997). Isso ocorre quanto a marca desempenha o papel de simbolizar associações feitas direta ou indiretamente às firmas (COSTA; ALMEIDA, 2012), além de apresentar características Revista Eletrônica do Alto Vale do Itajaí - REAVI, v.08, nº 13, p. 030-047, dez 2019 ISSN: 23164190, DOI 10.5965/2316419008112019030 


\section{REAVI}

intrínsecas da empresa para a sociedade (RAMASESHAN; TSAO, 2007). A importância da personalidade de uma marca reside, entre outros fatores, em sua capacidade de exercer influência na escolha do cliente e de ajudar a promover o relacionamento entre empresa e cliente (BIEL, 1993).

Finalmente, vale salientar o aspecto do posicionamento de marca, que diz respeito a como sua imagem é mostrada ao cliente (YAKIMOVA; BEVERLAND, 2005), muitas vezes, relacionando-a a seus competidores (PAHARIA; AVERY; KEINAN, 2014). Quando uma marca se posiciona, ela dá sinais aos consumidores de como eles devem percebê-la e avaliá-la (MONGA; GÜRHAN-CANLI, 2012), obviamente a partir de uma predeterminação do fabricante quanto ao tipo de público que deseja atingir e à estratégia de vendas que pretende abraçar (GIRALDI; SPINELLI; MERLO, 2003). Por seu turno, reposicionamentos podem ser necessários sempre que o fabricante sentir que há movimentos - do próprio cliente, dos concorrentes, do mercado de uma forma geral - que impliquem a necessidade de rever os parâmetros para poder subsistir (CHIABI; GONÇALVES, 2010; WANG; SHAVER, 2014).

\section{Método}

Quanto à abordagem, a presente pesquisa caracteriza-se como quantitativa, tendo utilizado recursos da estatística descritiva para a exposição dos resultados. No que diz respeito aos fins, trata-se de pesquisa descritiva; e quanto aos meios, é pesquisa bibliográfica e telematizada (VERGARA, 2016).

Para se responder à questão-problema de quais são as principais características metodológicas dos estudos científicos brasileiros publicados em Administração de Marketing sobre o tema marca nos últimos 11 anos, foi inicialmente realizada breve revisão da literatura para a confecção do referencial teórico do artigo, com base fundamentalmente em material produzido no ambiente norte-americano, em consideração ao fato de ali ter-se originado o Marketing de uma forma geral e de também ali desenvolver-se a pesquisa de ponta nesta área.

Uma vez feito isto, passou-se à consolidação da amostra a ser estudada. Para tanto, foram buscados artigos que apresentassem o termo marca simultaneamente no título e nas palavraschave, contidos na base de dados da biblioteca eletrônica de periódicos científicos Scientific Periodicals Electronic Library (SPELL).

A opção por essa base se deveu à sua reputação, vez que é mantida pela Associação Nacional de Pós-Graduação e Pesquisa em Administração (ANPAD), apresentando representação eficiente da produção científica brasileira nos assuntos das ciências sociais (ALVES et al., 2016).

O período de busca foi de janeiro de 2008 a fevereiro de 2018, extensão justificada pelo fato de ter resultado em total de 47 artigos, amostra considerada de tamanho razoável para a pesquisa proposta.

A obtenção das informações primárias se deu por meio da leitura dos 47 artigos da amostra, tendo sido transportado para planilha Excel o resultado da extração de 13 tipos de informações originadas em Visentini e Fenner (2017), guia que se justifica pelo fato de se tratar de artigo veiculado em periódico qualificado como B3 na lista Qualis da CAPES:

1. Evolução da publicação de artigos, ou seja, número de artigos publicados anualmente no período;

2. Natureza da pesquisa: teórica ou empírica, entendendo-se a segunda como aquela de "face empírica e fatual da realidade; produz e analisa dados, procedendo sempre pela via do controle empírico e fatual" (DEMO, 2000, p. 21). Já, a pesquisa teórica é aquela "dedicada a Revista Eletrônica do Alto Vale do Itajaí - REAVI, v.08, n 13, p. 030-047, dez 2019 ISSN: 23164190, DOI 10.5965/2316419008112019030 


\section{REAVI}

reconstruir teoria, conceitos, ideias, ideologias, polêmicas, tendo em vista, em termos imediatos, aprimorar fundamentos teóricos" (DEMO, 2000, p. 20);

3. Quantidade de autores por artigo;

4. Apresentação de justificativa para a realização da pesquisa;

5. Abordagem da pesquisa: qualitativa - que utiliza instrumentos qualitativos para se alcançar o objetivo pretendido - ou quantitativa, quando são utilizados instrumentos quantitativos para se alcançar o objetivo pretendido;

6. Técnica de amostragem: probabilística ou não probabilística. No caso da primeira, os indivíduos investigados possuem a mesma probabilidade de serem selecionados na amostra, o que não ocorre na segunda.

7. Identificação dos sujeitos participantes do estudo e tamanho da amostra;

8. Tipos de dados coletados: primários ou secundários. Dados primários são aqueles que estão sendo obtidos de forma inédita, enquanto dados secundários são aqueles já disponibilizados por algum tipo de fonte;

9. Identificação dos instrumentos de coleta de dados utilizados na pesquisa;

10. Procedimentos utilizados para a análise dos dados, dependendo de estes últimos serem qualitativos ou quantitativos. No primeiro caso, as técnicas mais comumente utilizadas são as análises de conteúdo e de discurso; no segundo caso, uma das técnicas mais utilizadas é a modelagem de equações estruturais;

11. Apresentação de sugestões para novas pesquisas;

12. Contextos ou setores em que a marca é estudada; e,

13. Identificação dos modelos de mensuração presentes nos estudos, considerando seu número de variáveis dependentes e independentes, quantidade de ordens, e construtos mais utilizados como variáveis.

Vale notar que a identificação destes elementos foi realizada apenas por meio da reprodução da informação respectiva contida explicitamente nos artigos. Ou seja, nada foi subentendido pelos pesquisadores que tomaram parte na confecção desta pesquisa.

Por exemplo, por mais que um autor da amostra informasse que tinha ido a campo entrevistar pessoas ou aplicar questionário inédito a determinada amostra (ambos os casos configurando-se como obtenção de informações primárias), ou que tivesse utilizado informações resultantes de levantamento bibliográfico (configurando-se como informações secundárias), os autores da presente pesquisa consideraram que esta qualificação só poderia constar para os cálculos da estatística descritiva proposta, se, nos textos dos artigos, tivessem encontrado explicitamente a menção ao uso de dados primários e/ou secundários. Ipso facto, quando estas explicitações não existiam, isto era reportado nas planilhas Excel como "não informado".

Uma vez executada a tarefa de cada um dos quatro pesquisadores da equipe, seus resultados foram agrupados em um único arquivo Excel, com as informações da amostra como um todo. Em seguida, foi executada a tabulação, tanto quantitativa quanto qualitativa, para atender aos 13 critérios propostos por Visentini e Fenner (2017), e os dados foram tratados por estatística descritiva, tendo sido elaborados gráficos e tabelas que lhes facilitassem o entendimento. Finalmente, foi redigido o texto contendo a descrição destes resultados — insumo fundamental para a elaboração da seção de considerações finais do artigo.

\section{Resultados do levantamento primário}

\subsection{Evolução da publicação de artigos}

Revista Eletrônica do Alto Vale do Itajaí - REAVI, v.08, n 13, p. 030-047, dez 2019 ISSN: 23164190, DOI 10.5965/2316419008112019030 


\section{REAVI}

Os anos de 2013, 2015 e de 2016 foram os de maior representatividade na distribuição anual dos artigos da amostra, com 44,7\% do total. Já 2008 e 2012 viram diminuir muito o interesse no tema, mostrando ausência de tendência clara no período de 11 anos avaliado (ver Gráfico 1).

Gráfico 1 - Quantidade Anual de Artigos da Amostra.

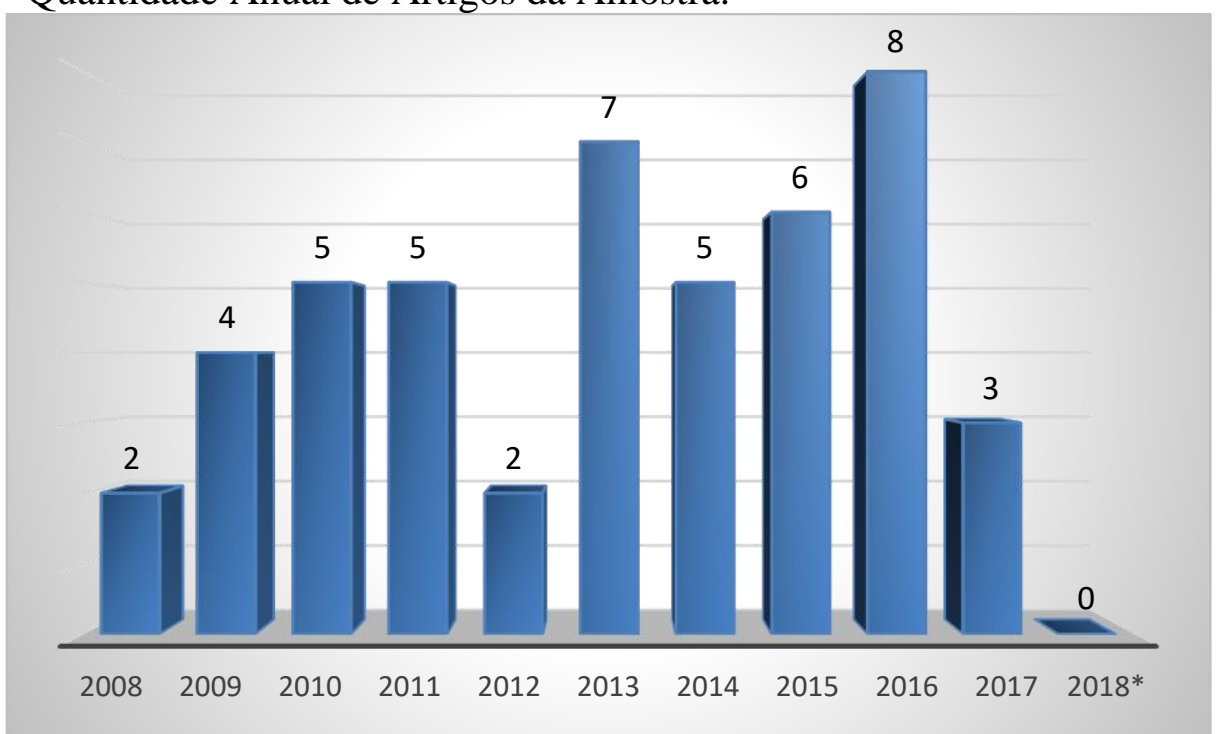

Fonte: Elaboração própria.

* Janeiro-fevereiro

\subsection{Natureza da pesquisa: teórica ou empírica}

Quase $80 \%$ dos artigos da amostra não trouxeram informação sobre o tipo de pesquisa executada - se teórica ou empírica. Dentre as que se preocuparam em explicitar esta característica, a maior parte declarou-se de natureza empírica (ver Gráfico 2)

\section{Gráfico 2 - Natureza da Pesquisa.}

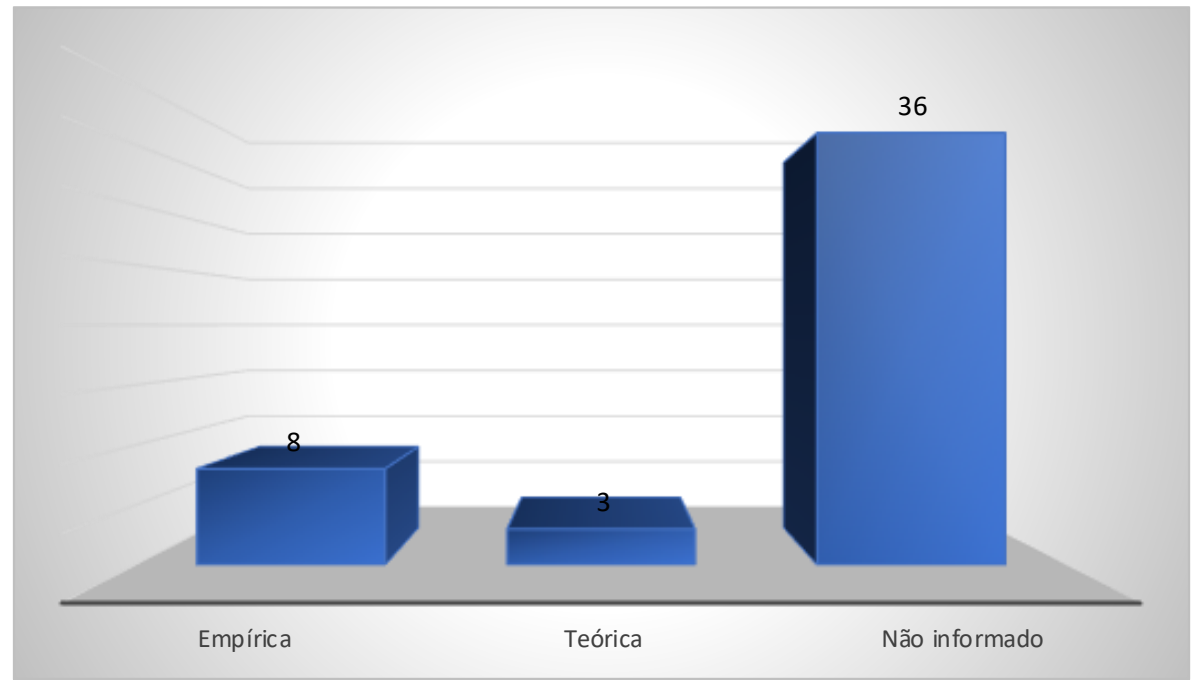

Fonte: Elaboração própria

Revista Eletrônica do Alto Vale do Itajaí - REAVI, v.08, nº 13, p. 030-047, dez 2019 ISSN: 23164190, DOI 10.5965/2316419008112019030 


\section{REAVI}

3.3 Número de autores por artigo

Quase metade da amostra foi formada por artigos com três autores; junto com os artigos com dois autores, estes dois casos chegaram a 72,3\% da amostra. Já, o caso em menor número foi o de cinco autores, com apenas dois casos (ver Gráfico 3).

Gráfico 3 - Quantidade de Autores por Artigo.

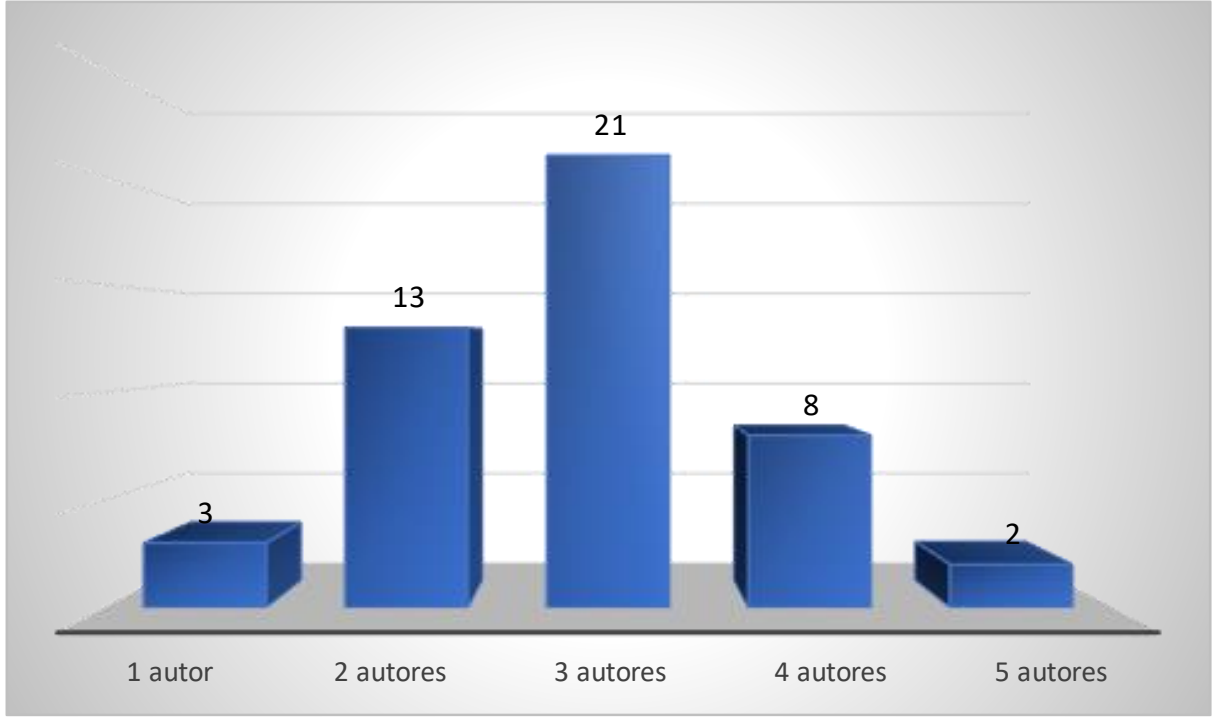

Fonte: Elaboração própria

3.4 Apresentação de justificativa para a realização da pesquisa

Todos os artigos da amostra apresentaram uma justificativa para sua pesquisa, sempre explicitada na seção de introdução (ver Gráfico 4).

Gráfico 4 - Apresentação de Justificativa.

47

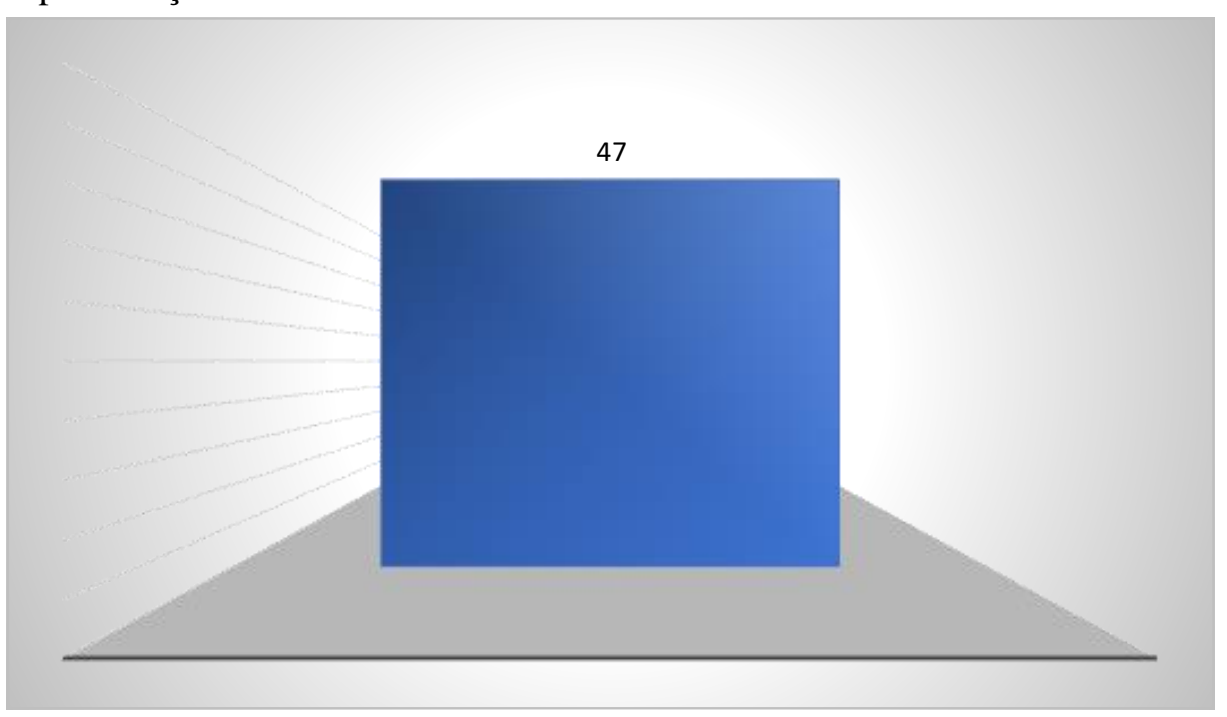

Fonte: Elaboração própria

Revista Eletrônica do Alto Vale do Itajaí - REAVI, v.08, n 13, p. 030-047, dez 2019 ISSN: 23164190, DOI 10.5965/2316419008112019030 


\section{REAVI}

\subsection{Abordagem da pesquisa}

Cerca de metade da amostra não informou o tipo de abordagem utilizada nas respectivas pesquisas. Dentre aquelas que o fizeram, $62,5 \%$ optaram pela abordagem qualitativa e tão somente 8,3\% preferiram a abordagem quali-quanti (ver Gráfico 5).

Gráfico 5 - Abordagem Adotada.

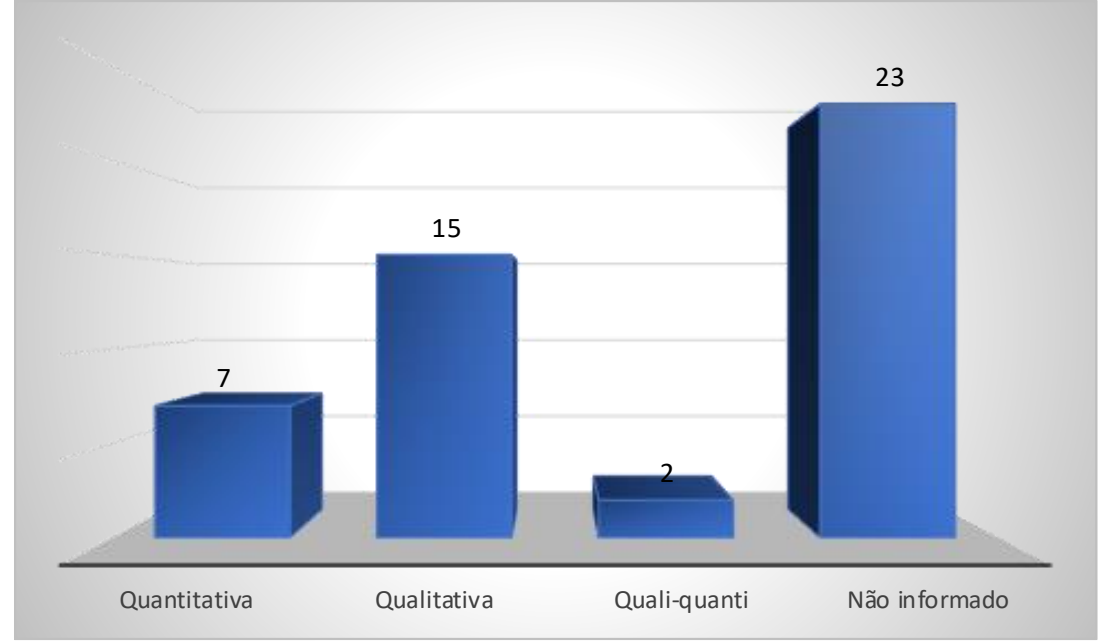

Fonte: Elaboração própria

\subsection{Técnica de amostragem}

Apenas 15 artigos da amostra informaram qual técnica de amostragem haviam adotado, perfazendo $31,9 \%$ da amostra. Considerando que, formalmente, esta informação diga respeito apenas às pesquisas quantitativas, infere-se que esta abordagem tenha sido adotada em mais do que apenas os nove artigos que declararam a terem utilizado (ver Gráfico 6).

Gráfico 6 - Técnica de Amostragem Adotada.

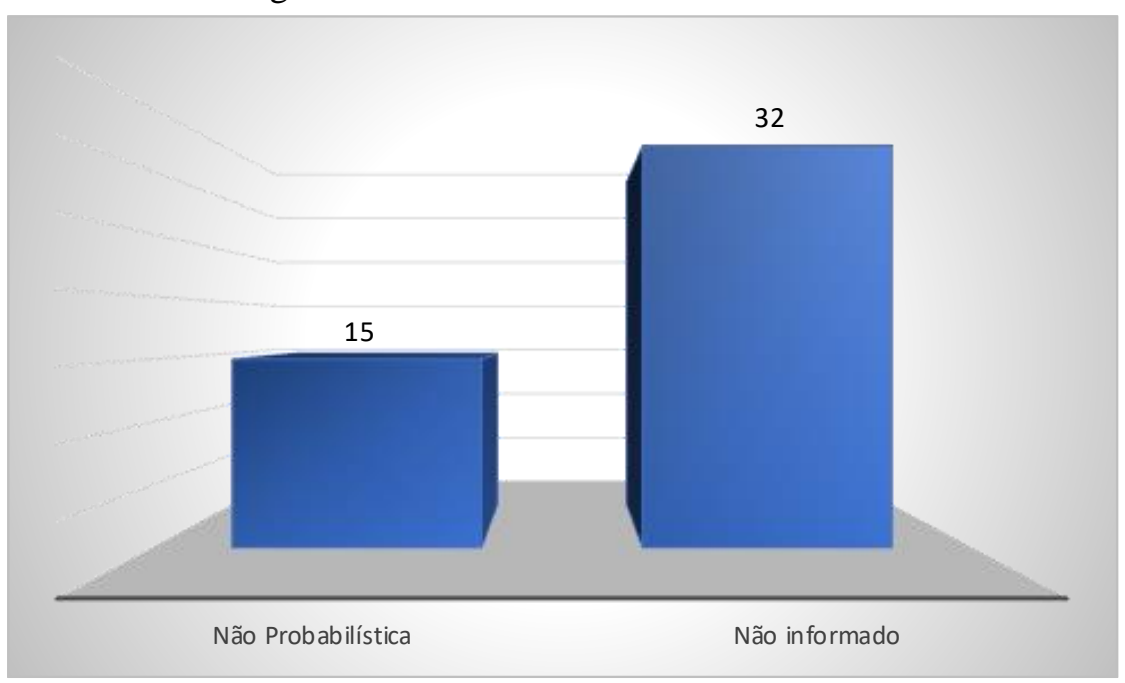

Fonte: Elaboração própria

Revista Eletrônica do Alto Vale do Itajaí - REAVI, v.08, n 13, p. 030-047, dez 2019 ISSN: 23164190, DOI 10.5965/2316419008112019030 


\section{REAVI}

3.7 Identificação dos sujeitos participantes do estudo e tamanho da amostra

Dentre os sujeitos pesquisados nos artigos da amostra estudada, 10 deles não especificaram esta informação. Já dentre aqueles que o fizeram, 43,2\% estudaram consumidores de uma forma geral, vindo em seguida estudantes (ver Gráfico 7).

Gráfico 7 - Tipos de Sujeitos Pesquisados.

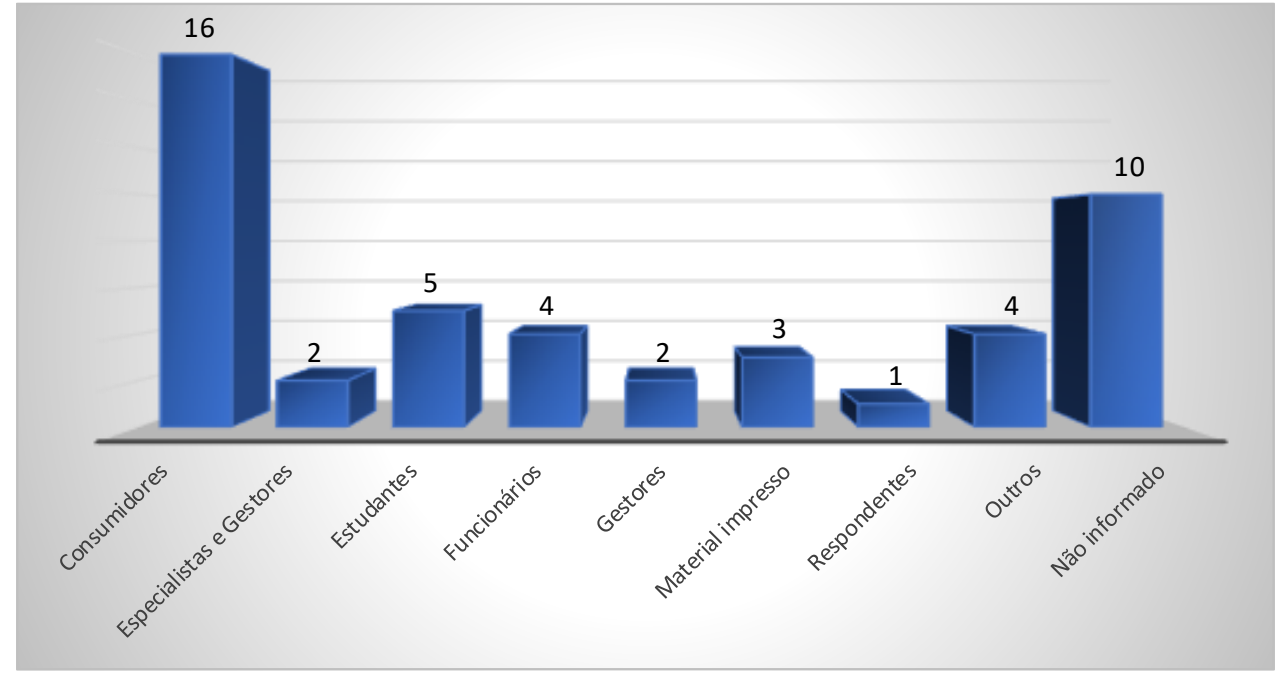

Fonte: Elaboração própria

\subsection{Tipos de dados coletados}

Quase $90 \%$ dos artigos da amostra não especificaram se os dados que coletaram para subsidiar seus respectivos estudos eram primários, secundários ou ambos. Dentre aqueles que o fizeram, a maior parte disse utilizar apenas dados secundários (ver Gráfico 8).

Gráfico 8 - Tipo de dados Coletados.

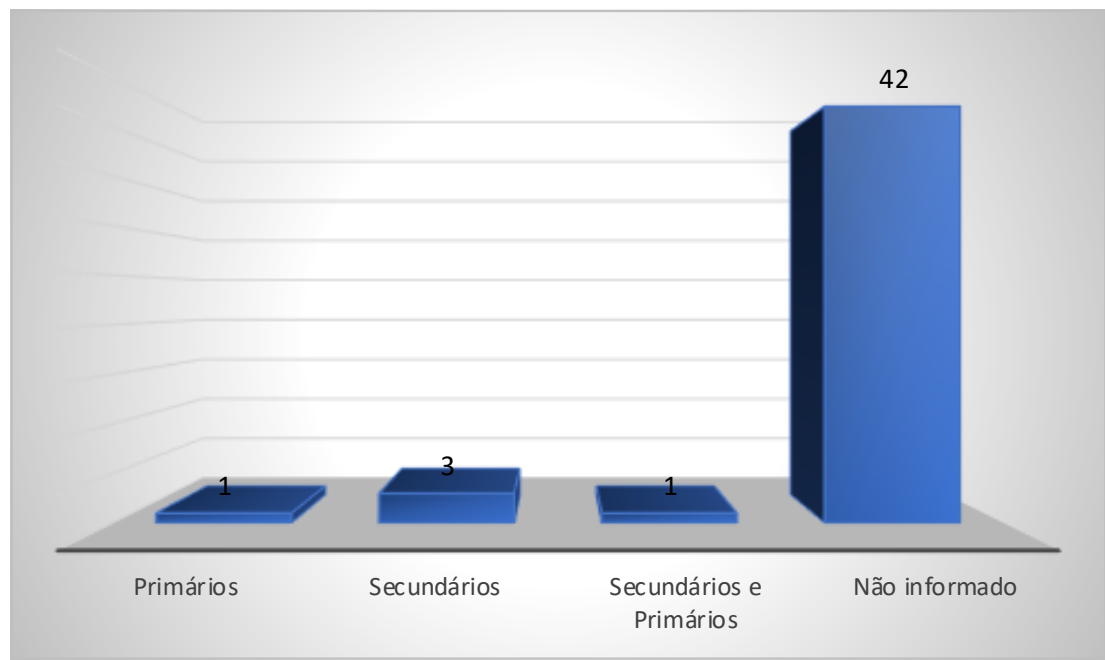

Fonte: Elaboração própria

Revista Eletrônica do Alto Vale do Itajaí - REAVI, v.08, n 13, p. 030-047, dez 2019 ISSN: 23164190, DOI 10.5965/2316419008112019030 


\section{REAVI}

3.9 Identificação dos instrumentos de coleta de dados utilizados na pesquisa

Quase 30\% dos artigos da amostra não forneceram esta informação, assim como três cometeram erro ao fazerem-no, pois disseram ter utilizado para tanto uma técnica de tratamento de evidências qualitativas - a análise de conteúdo. Dentre os 30 restantes, a entrevista e os questionários foram os instrumentos preferidos (ver Gráfico 9).

Gráfico 9 - Técnicas de Coleta de Dados.

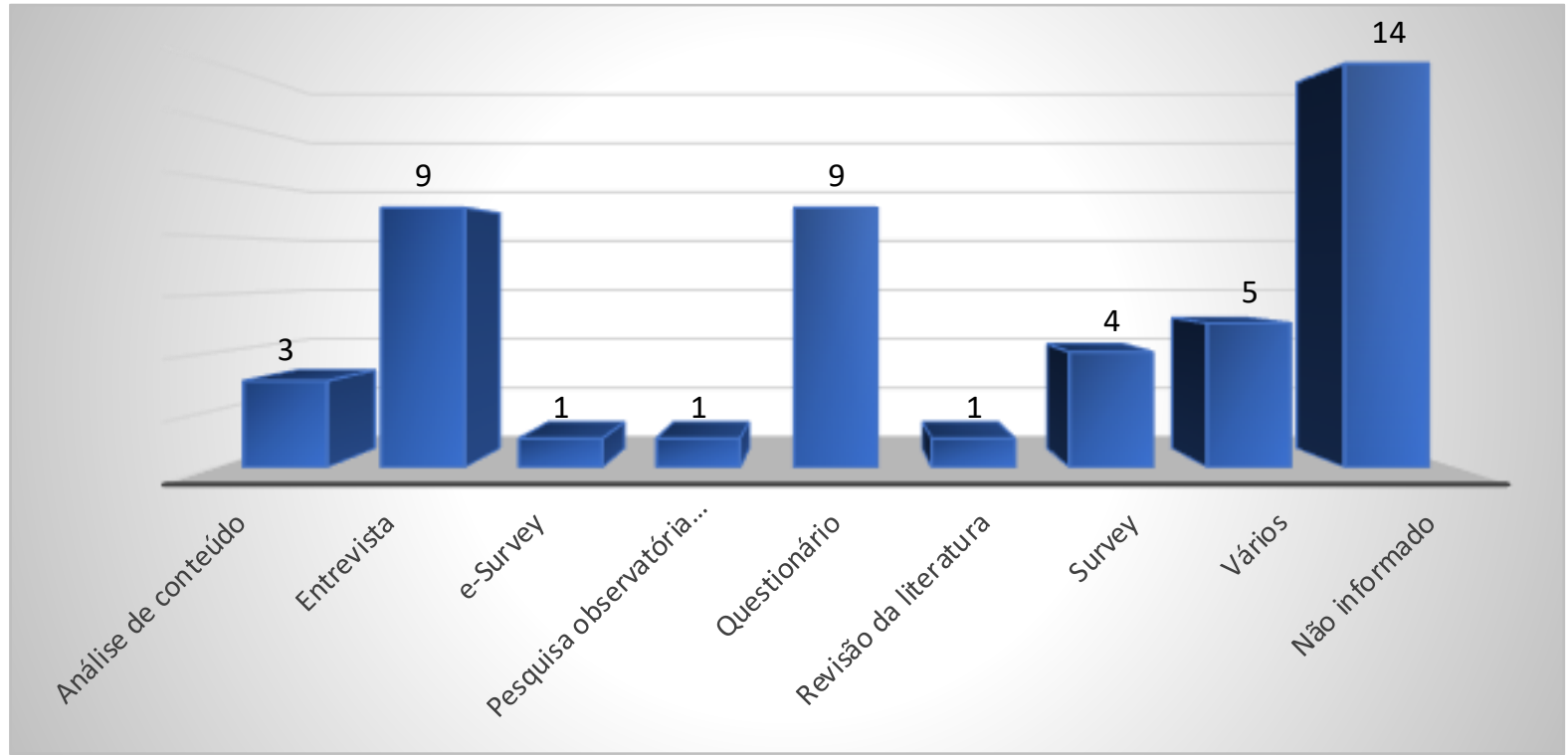

Fonte: Elaboração própria

\subsection{Procedimentos utilizados para a análise dos dados}

Trinta e quatro artigos da amostra, equivalendo a 72,3\% dela, não informaram a(s) forma(s) como analisaram os dados que utilizaram em suas pesquisas. Dentre os que o fizeram, a preferência ficou com a estatística descritiva, utilizada em quatro artigos (ver Gráfico 10).

Quanto às demais nove opções, houve um caso de falhas de interpretação, referido à técnica de exaustão. Referenciando-se a Fontanella, Ricas e Turato (2008), os autores Kappel e Paula (2016, p. 1191) da amostra aqui estudada dizem o seguinte: "Tratando-se de método de procedimento para análise de dados, o trabalho foi realizado por meio da técnica de exaustão (...)". Esta afirmação, contudo, não corresponde à realidade, porque aquela trinca de autores na verdade usa o termo para denominar a captação de elementos amostrais em que são incluídos todos os indivíduos disponíveis e não para denominar uma técnica de tratamento de dados.

Revista Eletrônica do Alto Vale do Itajaí - REAVI, v.08, nº 13, p. 030-047, dez 2019 ISSN: 23164190, DOI 10.5965/2316419008112019030 


\section{REAVI}

Gráfico 10 - Técnicas de Análise de Dados.

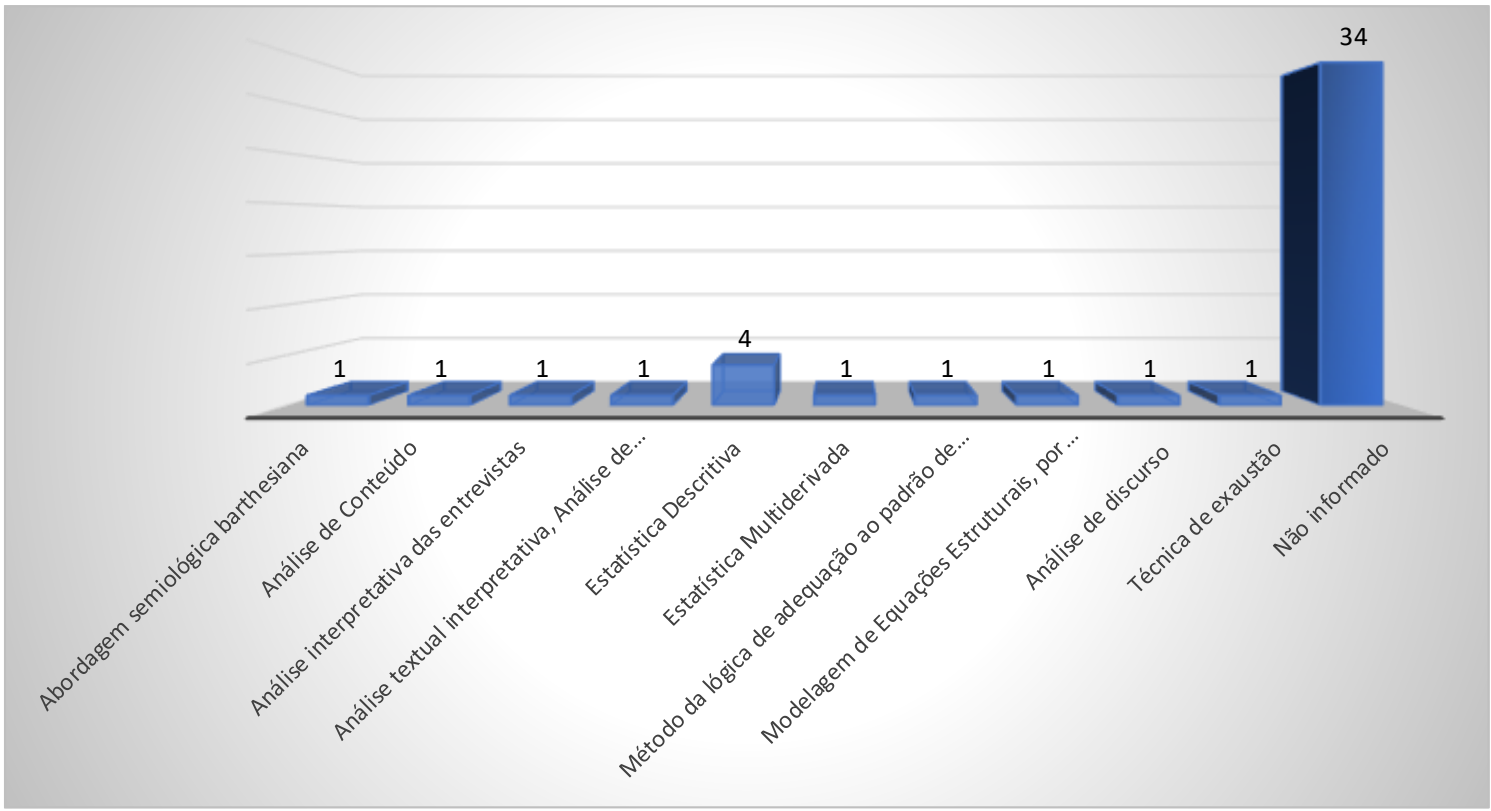

Fonte: Elaboração própria

3.11 Apresentação de sugestões para novas pesquisas

Sugestões de futuras pesquisas não foram apresentadas por 34\% da amostra (ver Gráfico 11).

Gráfico 11 - Sugestões de Pesquisas Futuras.

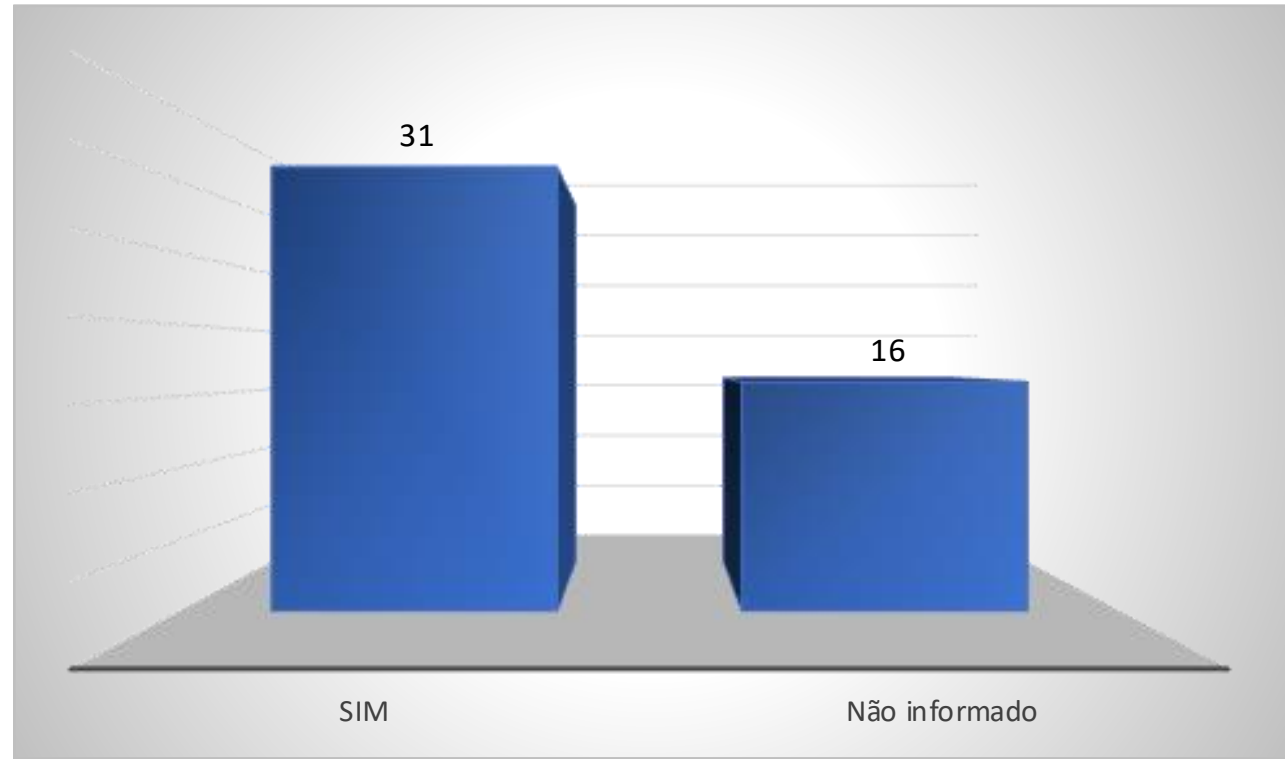

Fonte: Elaboração própria

Revista Eletrônica do Alto Vale do Itajaí - REAVI, v.08, nº 13, p. 030-047, dez 2019 ISSN: 23164190, DOI 10.5965/2316419008112019030 


\section{REAVI}

3.12 Contextos ou setores em que a marca é estudada

Houve 20 contextos contemplados na amostra estudada, sendo que os preferidos foram o comércio e os setores de bebidas e de moda (ver Gráfico 12).

Gráfico 12 - Contextos ou Setores de Estudo.

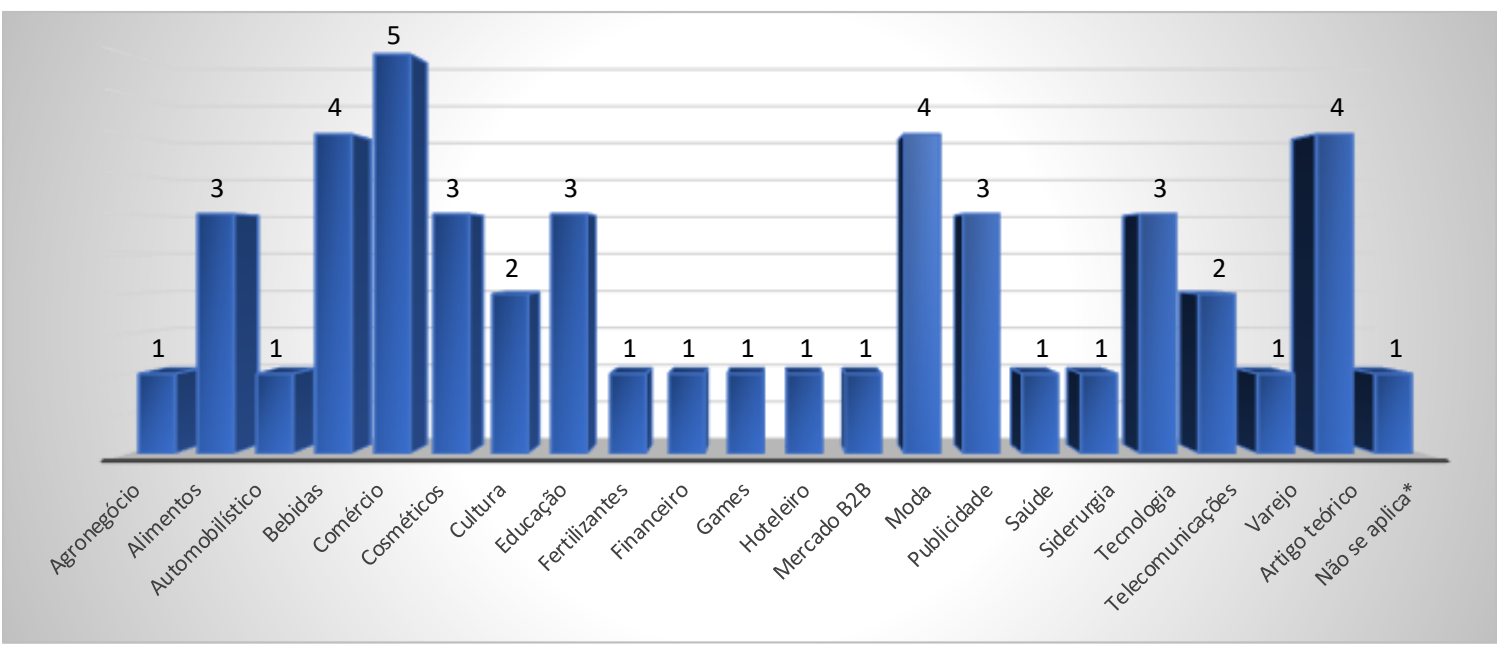

Fonte: Elaboração própria

* O estudo analisa o processo de construção das marcas presente no discurso editorial das marcas retratadas nas capas de cinco revistas.

\subsection{Identificação dos modelos de mensuração presentes nos estudos}

Nenhum dos artigos da amostra informou sobre os modelos de mensuração que porventura tenham utilizado, considerando seu número de variáveis dependentes e independentes, quantidade de ordens e construtos mais utilizados como variáveis.

\section{Conclusão}

O presente artigo atingiu seu propósito de indicar as principais características metodológicas dos estudos científicos brasileiros publicados de Marketing sobre o tema marca, nos últimos 11 anos, e que apresentaram o termo marca simultaneamente no título e nas palavraschave, contidos nos na base SPELL de dados da biblioteca eletrônica de periódicos científicos, no período de janeiro de 2008 a fevereiro de 2018. Tipicamente, eles foram escritos por três autores, concentraram-se em 2013 ou em 2016, tinham foco em consumidores de uma forma geral, estavam situados no segmento de comércio, apresentavam uma justificativa para a realização da investigação e traziam sugestões de futuras pesquisas.

Por outro lado, a maior parte — ou, em certos casos, todos — não traziam informação sobre tratar-se de pesquisa teórica ou empírica, nem sobre a abordagem utilizada, nem sobre a técnica de amostragem adotada, nem sobre o tipo de dados coletados, nem sobre as técnicas de coleta e de análise destes dados, assim como não identificavam os modelos de mensuração que porventura tivessem utilizado.

Este resultado serve à discussão sobre o porquê de os autores brasileiros, assim como os avaliadores dos periódicos onde estes artigos são veiculados, desprezarem o fornecimento explícito de informações sobre o método que utilizam em suas pesquisas.

Revista Eletrônica do Alto Vale do Itajaí - REAVI, v.08, nº 13, p. 030-047, dez 2019 ISSN: 23164190, DOI 10.5965/2316419008112019030 
Aparentemente, tanto os autores como os avaliadores da amostra aqui estudada esqueceram que a confiabilidade de um estudo acadêmico, enquanto sua capacidade de replicação por outros pesquisadores, constitui-se em exigência básica para garantir a qualidade de pesquisa que tenha a pretensão de se apresentar como verdadeiramente científica.

De fato, sob o paradigma construtivista, é de suma importância que estejam garantidas a credibilidade, a transferibilidade, a confiança e a confirmabilidade dessas pesquisas, principalmente no que tange aquelas realizadas sob a abordagem qualitativa (DENZIN; LINCOLN, 2006). No caso dos estudos quantitativos, esta importância também é significativa, sendo que, à confiabilidade e à validade de um instrumento de mensuração, une-se a objetividade, referida ao grau em que este mesmo instrumento é permeável à influência dos vieses e das tendências do pesquisador que a aplica, qualifica ou interpreta (SAMPIERI; COLLADO; LUCIO, 2013).

A existência desta lacuna é preocupante, porque mostra que os pesquisadores, independente da qualidade de seus respectivos trabalhos, não acham que seja relevante dar esse tipo de informação ao público.

No caso de assim agirem devido ao próprio desconhecimento a respeito destas classificações, isso suscita a preocupação quanto à capacidade desses pesquisadores em julgarem de forma adequada o enquadramento de suas pesquisas às tipologias.

No caso de assim agirem devido ao seu julgamento de que se trata de informações desnecessárias, isso suscita outra preocupação, quanto à sua capacidade de compreender a importância da explicitação metodológica na construção do saber acadêmico. Talvez eles julguem que a construção desse saber deve se preocupar apenas com os resultados de uma pesquisa aplicada, com as consequências práticas, com a contribuição ao estado da arte, desdenhando a atenção a aspectos do rigor metodológico — o que, de certa forma, retroalimenta a preocupação colocada no parágrafo anterior.

É possível que o desprezo, em maior ou menor grau, à menção explícita de aspectos metodológicos poderá sempre ser revidado, por parte de seus autores, com o argumento de que "os elementos estavam lá, só não apareciam de forma explícita”.

Nesse caso, deve-se contrapor que qualquer trabalho científico deve ser objetivo. Nele, nada deve ser deixado ao sabor das interpretações - quando mais não fosse, para possibilitar sua replicação por outros pesquisadores. Apoiado na monossemia, o gênero científico deve primar pela clareza e pela objetividade, de forma a evitar a duplicidade de interpretações (MICHEL, 2015).

A contribuição deste artigo à área de Administração de Empresas reside na sugestão de que o ensino de métodos de pesquisa nos ambientes acadêmicos seja reforçado. Um maior rigor nas aulas de metodologia da pesquisa ajudaria não só os trabalhos finais de curso, assim como os artigos científicos deles derivados, a conterem menos erros metodológicos. Em paralelo, também contribuiria para que os pesquisadores que se propõem a ser avaliadores de artigos científicos passassem a prestar mais atenção na seção do método, ao invés de se concentrarem naquilo que, normalmente, é considerado o mais importante de uma pesquisa primária: a seção dos resultados.

A presente pesquisa apresenta limitações, sendo a maior delas o fato de se restringir à amostra de conveniência, relativamente reduzida e concentrada em apenas uma base de periódicos. Por isso, futuras investigações podem replicá-la analisando artigos de bases pertencentes a periódicos de elevado padrão Qualis; isto permitiria ali verificar a eventual existência da lacuna aqui identificada. Também poderia ser discutida a qualidade com que foram enfocados os

Revista Eletrônica do Alto Vale do Itajaí - REAVI, v.08, n 13, p. 030-047, dez 2019 ISSN: 23164190, DOI 10.5965/2316419008112019030 


\section{REAVI}

elementos deste levantamento, para que os leitores possam entender como foram considerados ou desenvolvidos na pesquisa.

\section{REFERÊNCIAS}

AAKER, J. L. Dimensions of brand personality. Journal of Marketing Research, p. 347-356, 1997.

ALVES, J.; FLAVIANO, V.; KLEIN, L.; LÖBLER, M.; PEREIRA, B. A economia solidária no centro das discussões: um trabalho bibliométrico de estudos brasileiros. Cad. EBAPE.BR, v. 14, n. 2, p. 243-257, 2016.

AMA - American Marketing Association. Marketing Definitions: A Glossary of Marketing Terms. Chicago 1960.

AMA. American Marketing Association Dictionary-Official Definition of Brand. 2014. Disponível em <http://www.marketingpower.com/_layouts/Dictionary.aspx?dLetter $1 / 4 \mathrm{~B}>$. Acesso em 01 set 2019 .

BERTILSSON, J.; RENNSTAM, J. The destructive side of branding: A heuristic model for analyzing the value of branding practice. Organization, v. 25, n. 2, p. 260-281, 2018.

BIEL, A. Converting image into equity. In: AAKER, D. A., BIEL, A. (Org.). Brand equity and advertising: Advertising's role in building strong brand. Hillsdale, NJ: Laurence Erlbaum Associates, 1993.

BLACK, I.; VELOUTSOUB, C. Working consumers: Co-creation of brand identity, consumer identity and brand community identity. Journal of Business Research, v. 70, p. 416-429, 2017.

BOWDEN, J. L.; DAGGER, T. S.; ELLIOTT, G. The role of relational antecedents and the effect of experience in the development of service loyalty. Australian and New Zealand Marketing Academy (ANZMAC) Conference. Melbourne, 2009.

CHEKALINA, T.; FUCHS, M.; LEXHAGEN, M. Customer-Based Destination Brand Equity Modeling: The Role of Destination Resources, Value for Money, and Value in Use. Journal of Travel Research, v. 57, n. 1, p. 31-51, 2018.

CHIABI, A. L. G.; GONÇALVES, C. A. Análise de estratégia de mudança da marca acrescentando valor: um estudo da Vale. Revista de Administração da UFSM, v. 3, n.1, p. 131$143,2010$.

CONEJO, F.; WOOLISCROFT, B. Brands Defined as Semiotic Marketing Systems. Journal of Macromarketing, v. 35, n. 3, p. 287-301, 2015.

Revista Eletrônica do Alto Vale do Itajaí - REAVI, v.08, n 13, p. 030-047, dez 2019 ISSN: 23164190, DOI 10.5965/2316419008112019030 


\section{REAVI}

COSTA, L. S.; ALMEIDA, V. M. C. Valor da marca: teste empírico da importância das dimensões formadoras do valor da marca na perspectiva do consumidor no contexto brasileiro. Revista Brasileira de Marketing, v. 11, n. 2, p. 43, 2012.

CHRISTODOULIDES, G.; DE CHERNATONY, L. Consumer-based brand equity conceptualization and measurement: A literature review. International Journal of Market Research, v. 52, n. 1, p. 43-66, 2010.

DANAEI, H.; SOURANI, H. Evaluation brand equity from the customer perspective Based on Aaker's Model (Case Study: Mellat Bank in Torbat-e-Jam). International Academic Journal of Organizational Behavior and Human Resource Management, v. 3, n. 7, p. 1-7, 2016.

DATTA, H.; AILAWADI, K.; HEERDE, H. How Well Does Consumer-Based Brand Equity Align with Sales-Based Brand Equity and Marketing Mix Response? Journal of Marketing, v. 81, p. 1-20, 2017.

DEMO, P. Metodologia do conhecimento científico. São Paulo: Atlas, 2000.

DENZIN, N.; LINCOLN, Y. A disciplina e a prática da pequisa qualitativa. In: DENZIN, N.; LINCOLN, Y. E COLABORADORES. O planejamento da pesquisa qualitativa. Teorias e abordagens. Porto Alegre: Artmed, 2006.

FELDWICK, P. Do we really need brand equity? The Journal of Brand Management, v.4, n.1, p.9-28, 1996.

GARDNER, B.; LEVY, S. The product and the brand. Harvard Business Review, p. 33-9, Mar./Apr. 1955.

GIRALDI, J. M.; SPINELLI, P. B.; MERLO, E. Retail Store Image: Analysis of the implications for Store Positioning. REAd - Revista Eletrônica de Administração v.36, n.9, p. 203-222, 2003.

KELLER, K. Conceptualizing, measuring, and managing customer-based brand equity. Journal of Marketing, v.57, n.1, p.1-22, jan. 1993.

KELLER, K. L. Reflections on customer-based brand equity: perspectives, progress, and priorities. AMS Review, v. 6, n. 1-2, p. 1-16, 2016.

KELLER, K. L.; LEHMANN, D. R Brand and branding: Research findings and future priorities. Marketing Science, v. 25, n. 6, p. 740-759, 2006.

KELLER, K. L.; MACHADO, M. Gestão estratégica de marcas. São Paulo: Ed. Pearson, 2006.

LEÃO, A. L. M. S.; CAMARGO, T. I.; CAVALCANTI, R. C. T. Como uma onda no mar: a fluida personalidade da Movimento. BBR-Brazilian Business Review, v. 10, n. 3, p. 34-53, 2003.

Revista Eletrônica do Alto Vale do Itajaí - REAVI, v.08, n 13, p. 030-047, dez 2019 ISSN: 23164190, DOI 10.5965/2316419008112019030 


\section{REAVI}

MICHEL, M. H. Metodologia e pesquisa científica em ciências sociais: Um guia prático para acompanhamento da disciplina e elaboração de trabalhos monográficos. São Paulo: GEN/Atlas, 2015.

MONGA, A.; GÜRHAN-CANLI, Z. The influence of mating mind-sets on brand extension evaluation. Journal of Marketing Research, v. 49, n. 4, p. 581-593, 2012.

MONTOYA, N. ¿Qué es el estado del arte? Ciencia y Tecnología para la Salud Visual y Ocular, v. 5, Julio-diciembre, p. 73-75, 2005.

OLIVEIRA-CASTRO, J. M.; FOXALL, G. R.; JAMES, V. K.; POHL, R. H.; DIAS, M. B.; CHANG, S. W. Consumer-based brand equity and brand performance. The Service Industries Journal, v. 28, n. 4, p. 445461, 2008.

PAHARIA, N.; AVERY, J.; KEINAN, A. Positioning Brands Against Large Competitors to Increase Sales. Journal of Marketing Research, v. 51, n. 6, p. 647-656, 2014.

PALMER, A. Customer experience management: a critical review of an emerging idea. Journal of Services Marketing, v. 24, n. 3, p. 196-208, 2010.

PORTO, R. Consumer-based brand equity of products and services: Assessing a measurement model with competing brands. Brazilian Journal of Marketing, v. 17, n.2, p. 150-165, 2018.

RAGGIO, R. D.; LEONE, R. P. The TheoreticalS eparation of Brand Equity and Brand Value: managerial implications for strategic planning. Journal of Brand Management, v.14, p.380-395, Mar. 2007.

RAITHEL, S.; TAYLOR, C.; HOCK, S. Are Super Bowl ads a super waste of money? Examining the intermediary roles of customer-based brand equity and customer equity effects. Journal of Business Research, v. 69, n. 9, September, p. 3788-3794, 2016.

RAMASESHAN, B.; TSAO, H. Moderating effects of the brand concept on the relationship between brand personality and perceived quality. Journal of Brand Management, v. 14, n. 6, p. 458-466, 2007.

SAMPIERI, R.; COLlADO, C.; LUCIO, M. Metodologia de Pesquisa. São Paulo: McGrawHill, 2013.

SHANKAR, V.; AZAR, P.; FULLER, M. Bran*eqt: a model and simulator for estimating, tracking, and managing multicategory brand equity. MSI Trustees Meeting, San Francisco, 2007.

THEURER, C.; TUMASJAN, A.; WELPE, I.; LIEVENS, F. Employer Branding: A Brand Equitybased Literature Review and Research Agenda. International Journal of Management Reviews, v. 20, p. 155-179, 2018.

Revista Eletrônica do Alto Vale do Itajaí - REAVI, v.08, n 13, p. 030-047, dez 2019 ISSN: 23164190, DOI 10.5965/2316419008112019030 


\section{REAVI}

TRINTA, J. L. Metodologias Financeiras para Avaliação de Marcas. $3^{\circ}$ Congresso de Comunicação e Marketing - CENPRO. Fundação Getúlio Vargas. 2006.

VERGARA, S. C. Projetos e relatórios de pesquisa em administração. São Paulo: GEN/Atlas, $16^{\mathrm{a}}$ ed., 2016.

VISENTINI, M.; FENNER, V. Lealdade: análise da produção científica brasileira na área de Marketing no período compreendido entre 2010 e 2016. Perspectivas em Gestão \& Conhecimento, v. 7, n. 2, p. 175-198, jul./dez. 2017.

WANG, R. D.; SHAVER, J. M. Competition-driven repositioning. Strategic Management Journal, v. 35, n. 11, p. 1585-1604, 2014.

WOOD, L. Brands and brand equity: definition and management. Management Decision, v.38, n.9, p.662-669, 2000.

YAKIMOVA, R.; BEVERLAND, M. The brand-supportive firm: An exploration of organizational drivers of brand updating. Journal of Brand Management, v.12, n.6, p. 445-460, 2005.

YANG, Y.; LIU, X.; LI, J. How Customer Experience Affects the Customer Based Brand Equity for Tourism Destinations. How Customer Experience Affects the Customer-Based Brand Equity for Tourism Destinations. Journal of Travel \& Tourism Marketing, DOI: 10.1080/10548408.2014.997959, 2015.

Revista Eletrônica do Alto Vale do Itajaí - REAVI, v.08, n 13, p. 030-047, dez 2019 ISSN: 23164190, DOI 10.5965/2316419008112019030 